\title{
Design of Ericsson Heat Engine with Micro Channel Recuperator
}

\author{
Ernst Kussul, ${ }^{1}$ Oleksandr Makeyev, ${ }^{2}$ Tatiana Baidyk, ${ }^{1}$ and Omar Olvera ${ }^{1}$ \\ ${ }^{1}$ Center of Applied Sciences and Technological Development (CCADET), National Autonomous University of Mexico, \\ (UNAM), Circuito Exterior Ciduad Universitaria, Coyoacan, 04510 Mexico City, DF, Mexico \\ ${ }^{2}$ University of Rhode Island, Kingston, RI 02881, USA \\ Correspondence should be addressed to Ernst Kussul, ekussul@unam.mx
}

Received 6 September 2012; Accepted 1 October 2012

Academic Editors: B. Limmeechokchai and Z. Oktay

Copyright () 2012 Ernst Kussul et al. This is an open access article distributed under the Creative Commons Attribution License, which permits unrestricted use, distribution, and reproduction in any medium, provided the original work is properly cited.

Stirling cycle and Rankine cycle heat engines are used to transform the heat energy of solar concentrators to mechanical and electrical energy. The Rankine cycle is used for large-scale solar power plants. The Stirling cycle can be used for small-scale solar power plants. The Stirling cycle heat engine has many advantages such as high efficiencyand long service life. However, the Stirling cycle is good for high-temperature difference. It demands the use of expensive materials. Its efficiency depends on the efficiency of the heat regenerator. The design and manufacture of a heat regenerator are not a trivial problem because the regenerator has to be placed in the internal space of the engine. It is possible to avoid this problem if we place the regenerator out of the internal engine space. To realize this idea it is necessary to develop the Ericsson cycle heat engine. We propose theoretical model and design of this engine.

\section{Introduction}

There are many different sources of sustainable energy. Indirectly many of them are produced as a result of solar activity, but usually the term "solar energy" means direct transformation of sun light to other types of energy. There are different types of solar energy plants. In this paper we will consider a Solar Thermal Energy System (STES). STES consists of a solar concentrator, a heat engine, and a generator of electric current. Sometimes it also includes an energy storage system. The solar concentrator permits us to obtain the high temperature needed for heat engines. In our previous work we described a low-cost solar concentrator based on multiple triangular flat facets [1-3]. Two prototypes of the solar concentrators are presented in Figures 1(a) and 1(b).

Two types of heat engines are usually used now in STES: steam turbines and Stirling engines [4-7]. Steam turbines are good for large power plants, and Stirling engines are proposed for distributed installations. The Stirling engine in general has high efficiency, long service life, and many other useful properties, but in existing versions it demands high-temperature difference [8] and for this reason demands expensive materials. This leads to elevated cost of this engine.
The Ericsson Cycle Heat Engine at present is investigated not so good as the Stirling Engine, but it has many promising properties and can be considered as a good candidate for STES [9-11].

\section{Stirling Engine}

The scheme of Stirling engine is shown in Figure 2, it contains a hot cylinder, a heater, a regenerator, a cooler, a cold cylinder, and 2 crankshafts that drive the pistons of the hot cylinder and the cold cylinder. The crankshafts are connected to the gears so that the hot cylinder crankshaft is displaced $90^{\circ}$ relative to the cold cylinder crankshaft. This displacement ensures the compression of the working liquid in the cold cylinder. After compression the working liquid is displaced from the cold cylinder to the hot cylinder. During this displacement the working liquid is heated to the temperature of the hot cylinder. In the hot cylinder the working liquid is expanded and produces more work than that was spent during its compression in the cold cylinder. Thereafter the working liquid is moved from the hot cylinder to the cold cylinder. 


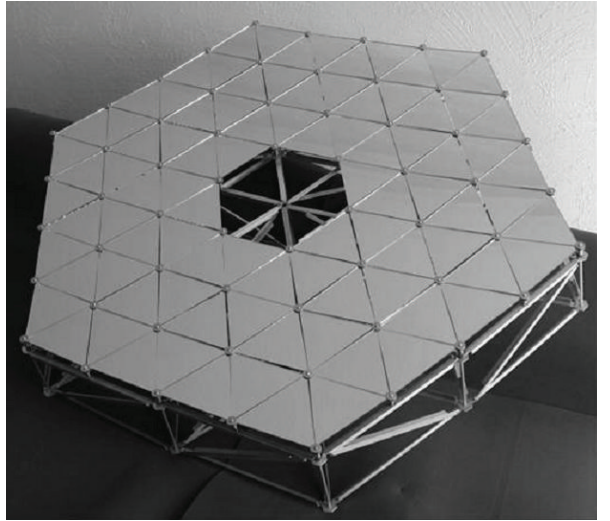

(a)

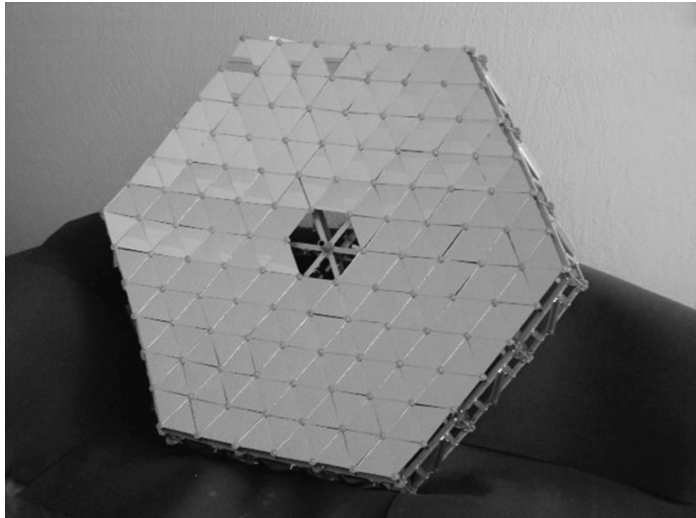

(b)

FIgURE 1: Two prototypes of the solar concentrators.

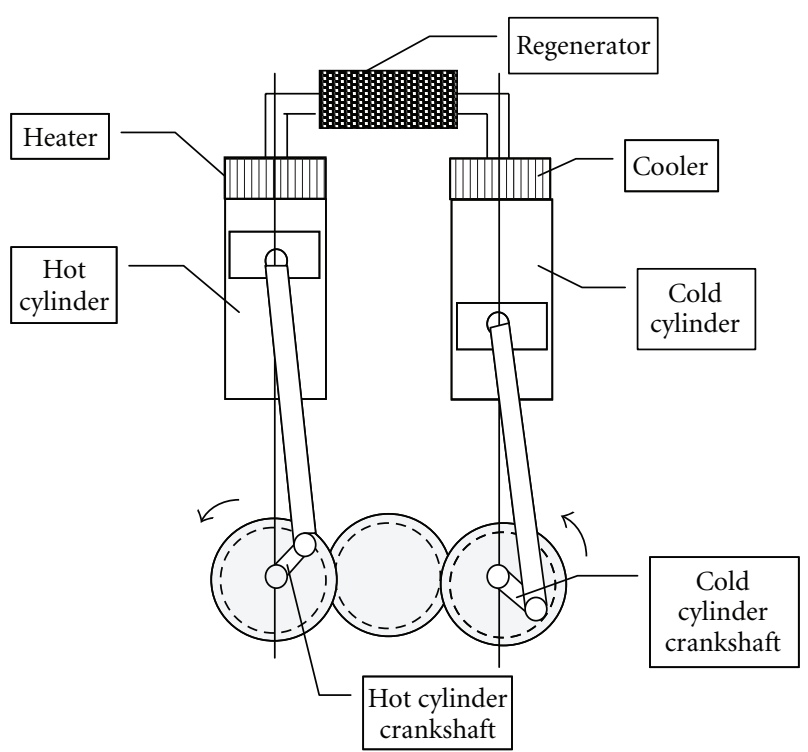

Figure 2: Stirling engine.

The Stirling engine has a simple structure without valves. But the simple structure of the Stirling engine generates many problems. In theory the Stirling cycle consists of the following processes:

(i) isothermal compression,

(ii) heating at constant volume,

(iii) isothermal expansion,

(iv) cooling at constant volume.

Real Stirling engines at present have no isothermal processes. To approximate the compression and expansion of the working fluid to the isothermal processes it is necessary to increase the thermal conductivity of working fluid, to decrease the rotation speed of the engine or to decrease the size of the cylinders. To increase the thermal conductivity modern Stirling engines use Hydrogen or Helium instead of air. The thermal conductivity of Helium and Hydrogen is 6-7 times higher than the thermal conductivity of air. However, it is not sufficient to obtain the compression and expansion processes close to the isothermal process. Practically it is impossible to decrease the speed of rotation of the engine to obtain isothermal compression and expansion because in this case the specific power (the relation of the power to the engine weight) drastically decreases. In principle it is possible to obtain isothermal processes if we decrease the sizes and increase the number of the cylinders. A rough estimation shows that it is possible to obtain good approximation to isothermal processes if the engine of $1 \mathrm{kWt}$ has about $1,000,000$ cylinders of sizes less than $1 \mathrm{~mm}$. At present we have no technology to produce such engines.

At present existing Stirling engines have compression and expansion processes that are closer to adiabatic processes than to isothermal processes. The difference between these processes is small if the compression and expansion rate is low. For example, if the coefficient of compression is 1.1 $(10 \%)$, the change of the temperature in adiabatic processes for Hydrogen is less than 3\%, and the process can be considered as quasi-isothermal. Normal engines with small coefficient of compression have low power. To preserve acceptable power the pressure in all the space of the engine is made high (e.g., 100 bar). In this case the pressure difference is sufficiently large (10 bar), and the engine has acceptable power. These conditions demand the development of a regenerator of very high efficiency. Real regenerators do not permit us to obtain Carnot efficiency (efficiency of an engine divided by efficiency of Carnot cycle) of Stirling engines more than 0.6. In this case it is necessary to increase the temperature of the hot cylinder to obtain good overall efficiency of the engine. High temperature of the hot cylinder demands the use of special materials that increase the cost of the engine.

\section{Ericsson Engine}

It is possible to propose another method to obtain approximately isothermal processes of compression and expansion. 
This method is used in some multistage gas turbines where the gas is cooled during the compression stages and is heated during the expansion stages. The method can also be used in piston engines including relatively low-power engine but in piston engines it demands the use of valves and cannot be realized in Stirling engine, but can be realized in Ericsson engine. An example of Ericsson engine is described in [11]. The engine power is $10.8 \mathrm{kWt}$. It is based on the open cycle; that is, the air from atmosphere enters to the two stage compressor with intermediate cooling. Compressed air enters to the recuperator at the temperature of $146^{\circ} \mathrm{C}$ and the pressure of $600 \mathrm{kPa}$. In the recuperator it is heated up to $379^{\circ} \mathrm{C}$ and after that enters to the heater, where its temperature increases to $800^{\circ} \mathrm{C}$. With this temperature the air goes to the expander where its temperature drops down to $405^{\circ} \mathrm{C}$ due to almost adiabatic expansion. After expander the air flows through the recuperator where it is cooled down to $172^{\circ} \mathrm{C}$. At this temperature the air goes to the atmosphere.

The theoretical Ericsson cycle is made up of two isothermal processes and two isobaric processes. As it was mentioned in [11] this theoretical cycle is not appropriate to study Ericsson engine. Really, the theoretical Ericsson cycle demands an isothermal expansion of the air, and the engine described in [11] has almost adiabatic expansion process where temperature drops from $800^{\circ} \mathrm{C}$ to $405^{\circ} \mathrm{C}$. To improve real Ericsson cycle it is necessary to decrease compression (and expansion) rate from 6 in the mentioned engine to 1.21.4. With this compression ratio the adiabatic process has small difference from the isothermal process, but in this case the power of the engine will decrease. To restore the engine power it is possible to make a multistage compression with the intermediate cooling and a multistage expansion with intermediate heating $[12,13]$. This type of engine is shown in Figure 3. It is possible to increase additionally the engine power if we will use the closed thermal cycle instead of open cycle used in [11]. The closed cycle permits us to increase the total pressure in the engine space. In our example we consider the total pressure equal to 20 bars.

The engine presented in Figure 3 consists of 3 compressors, 3 coolers, 3 expanders, 3 heaters, and recuperator. The number of the compressors, expanders, coolers, and heaters can be more than 3 . The coolers are placed at the input of each compressor, and the heaters are placed at the input of each expander. The Ericsson engine uses a recuperator instead of the regenerator that is used in the Stirling engine. The recuperator has two areas: the first area contains highpressure gas obtained from the compressors and the second area contains low-pressure gas obtained from the expanders. The heat exchanger of the recuperator permits heating of the compressed gas using the heat energy of the expanded gas.

The Ericsson engine works as follows: the working gas that is cooled in the recuperator and in the first cooler is compressed in the first compressor. The compression rate at this stage is as low as in the Stirling engine. The temperature of the gas at the compressor output is slightly higher than the temperature at the compressor input. After the first compressor the gas flows to the cooler that decreases its temperature. After that gas flows to the second compressor, where its pressure and temperature increase, but the temperature is returned to its previous value in the third cooler. In principle many stages of compression and cooling may be used to obtain a quasi-isothermal process of compression with high compression rate. A similar process occurs at the expansion of the gas. The difference is that we use expanders instead of compressors and heaters instead of coolers.

The proposed design of the engine permits us to obtain acceptable approximation of isothermal processes preserving high compression and expansion rates and acceptable specific power of the engine. In this case the influence of the recuperator parameters on the overall performance will be lower than in the Stirling engine, and that is why the Ericsson engine can have higher Carnot efficiency than the Stirling engine.

In this engine $P_{i}$ means the pressure, $T_{i}$ means the absolute temperature, and $v_{i}$ means specific volume of the gas in different points shown in Figure 3. The parameters of Ericsson engine were calculated using the program in $\mathrm{C}++$. The results are presented in Table 1 for different engine versions. $P_{1}=20$ bar is the pressure of the gas at the input of the first compressor, $\lambda$ is the compression rate in one compressor or expansion rate in one expander, $T_{c}=273^{\circ} \mathrm{K}$ is the temperature of the cool liquid at the input of Ericsson engine, $T_{h}$ is the temperature of hot liquid at the input of the Ericsson engine, $\Delta T_{c 1}$ is the temperature difference between the gas and cooling liquids in the coolers, $\Delta T_{h 6}$ is the temperature difference between the gas and hot liquids in the heaters, $\Delta T_{3-2}$ is the temperature difference between the lowpressure and the high-pressure gas in the recuperator at the compressor side, $\Delta T_{5-4}$ is the temperature difference between the low-pressure and the high-pressure gas in the recuperator at the expander side, $V_{1}=0.01 \mathrm{~m}^{3} / \mathrm{s}$ is the volumetric gas flow rate at the input of the first compressor, $W$ is the engine power, $\eta_{T}$ is the thermal efficiency of the Ericsson engine, $\eta_{C}$ is the efficiency of Carnot, $\eta_{T C}$ is the relation of thermal efficiency of the Ericsson engine to the efficiency of Carnot (in the literature this is termed as Carnot efficiency).

In our case the highest temperature of Ericsson engine is $573^{\circ} \mathrm{K}\left(300^{\circ} \mathrm{C}\right)$. This temperature permits us to use synthetic lubrication oils in all parts of Ericsson engine. Using of lubrication increases the service life and mechanical efficiency of the engine.

To create the Ericsson heat engine it is necessary to implement compressors, expanders, coolers, heaters, and recuperator. In this paper we describe the design of compressors, expanders, and recuperator. All compressors and expanders have the same design shown in Figure 4 but differ in sizes and/or rotation speed.

The intake piston and exhaust piston periodically open and close the intake windows and exhaust windows.

The compressor takes the gas from the intake port, slightly compresses it, and pushes the gas through the exhaust port. The expander receives the compressed hot gas from the intake port, allows the gas to expand, and pushes it through exhaust port. Low compression and expansion rate in each main cylinder permits us to consider the process as an isotermal one. 
TABLE 1: Ericsson engine parameters.

\begin{tabular}{lcccccccccc}
\hline Engine version & $\lambda$ & $T_{h}\left({ }^{\circ} \mathrm{K}\right)$ & $\Delta T_{c 1}\left({ }^{\circ} \mathrm{K}\right)$ & $\Delta T_{h 6}\left({ }^{\circ} \mathrm{K}\right)$ & $\Delta T_{3-2}\left({ }^{\circ} \mathrm{K}\right)$ & $\Delta T_{5-4}\left({ }^{\circ} \mathrm{K}\right)$ & $W$ & $\eta_{T}$ & $\eta_{C}$ & $\eta_{T C}$ \\
\hline 1 & 1.2 & 573 & 5 & 5 & 10 & 10 & 10548 & 0.432 & 0.524 & 0.825 \\
2 & 1.2 & 573 & 3 & 3 & 5 & 5 & 10783 & 0.461 & 0.524 & 0.88 \\
3 & 1.4 & 573 & 3 & 3 & 5 & 5 & 18559 & 0.45 & 0.524 & 0.86 \\
4 & 1.4 & 453 & 3 & 3 & 5 & 5 & 10191 & 0.31 & 0.397 & 0.78 \\
5 & 1.4 & 453 & 5 & 5 & 10 & 10 & 9827 & 0.291 & 0.397 & 0.73 \\
6 & 1.2 & 573 & 13 & 13 & 26 & 26 & 9641 & 0.35 & 0.524 & 0.67 \\
\hline
\end{tabular}

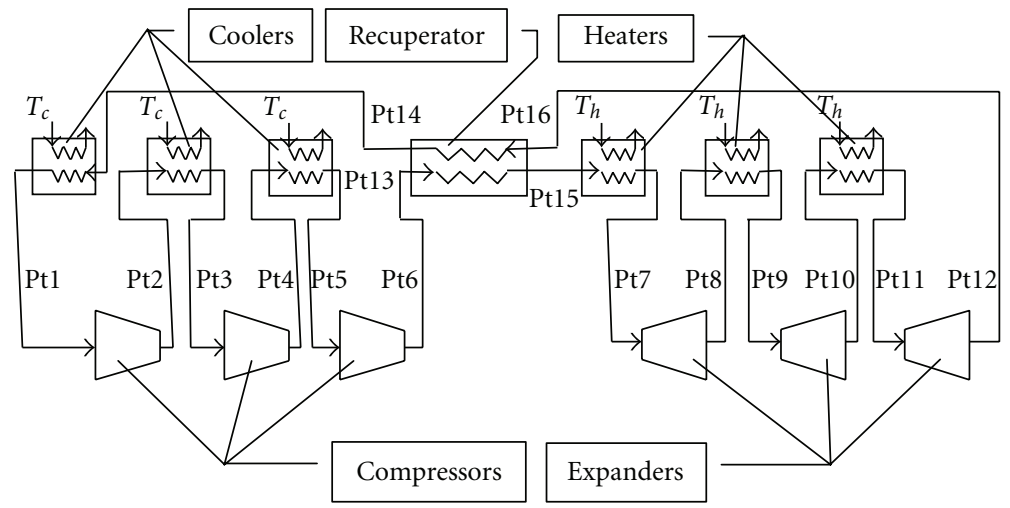

Figure 3: Ericsson engine $\left(P t_{i} \rightarrow P_{i}, T_{i}\right)$.

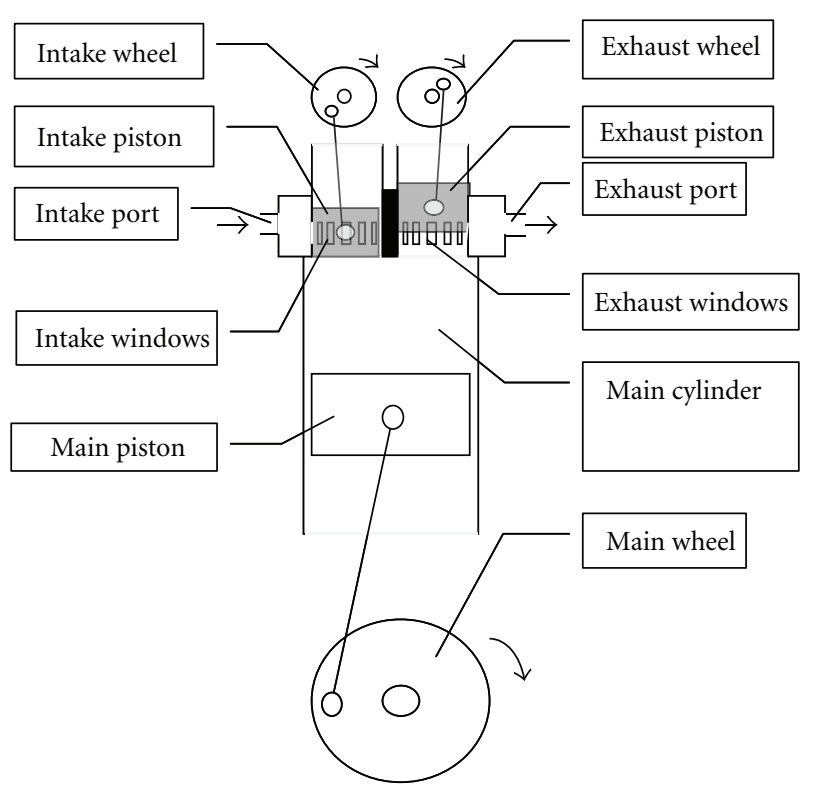

FIGURE 4: Scheme of compressor/expander for Ericsson heat engine.

\section{MicroChannel Recuperator}

The main element of microchannel recuperator is its base plate. The base plate is circular plate from the metal with high thermal conductivity (e.g., copper or aluminum) (Figure 5). This plate contains several circles of holes that form microchannels for compressed and expanded air. Each circle for compressed air (excluding external circle) is located between two circles for expanded air, and each circle for

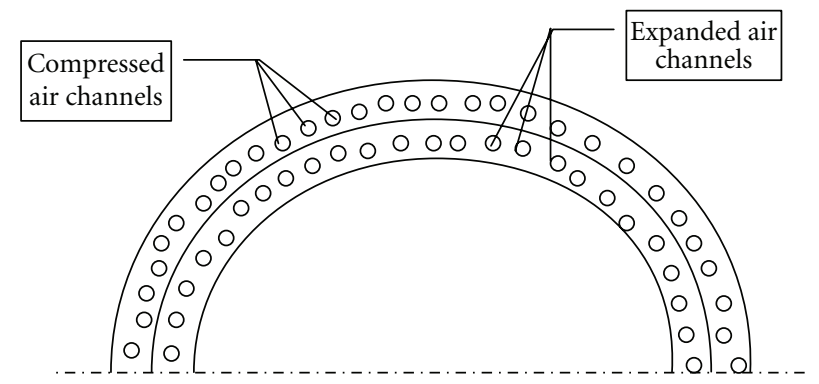

Figure 5: Base plate of micro channel recuperator.

expanded air (excluding internal circle) is located between two circles for compressed air. In Figure 5 only two circles are presented. The micro channel recuperator contains many base plates separated by sealing rings (Figure 6) in the manner that each zone of compressed and expanded air is hermetically sealed.

In Figure 7 we present the fragment of micro channel recuperator.

In this figure $S$ stands for the radial distance between the hole circles, $H$ is the tangential distance between the holes, $D$ is the diameter of micro channel, $L$ is the thickness of the disk, and $T$ is the step of the disks in the recuperator. The calculations of recuperator parameters are presented in appendix. This recuperator must work with the Ericsson engine shown in line 2 of Table 1. The engine has very high theoretical efficiency ( $88 \%$ from the corresponding Carnot cycle) but needs low-temperature difference $\left(5^{\circ} \mathrm{C}\right)$ between hot air and cold air in the recuperator. This 


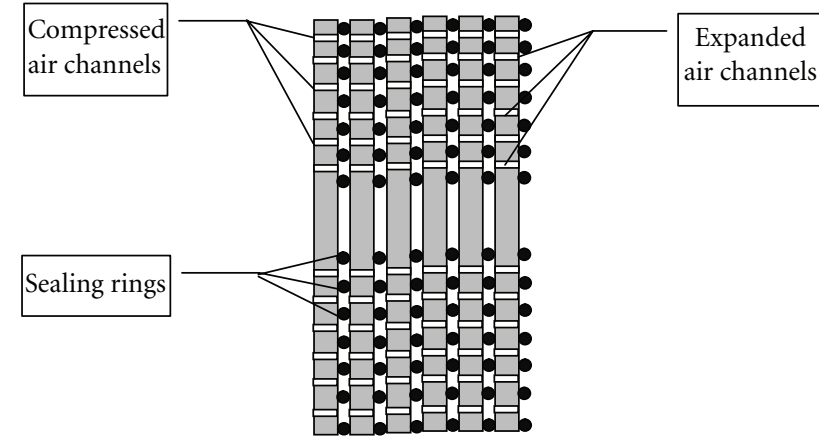

Figure 6: Microchannel recuperator design.

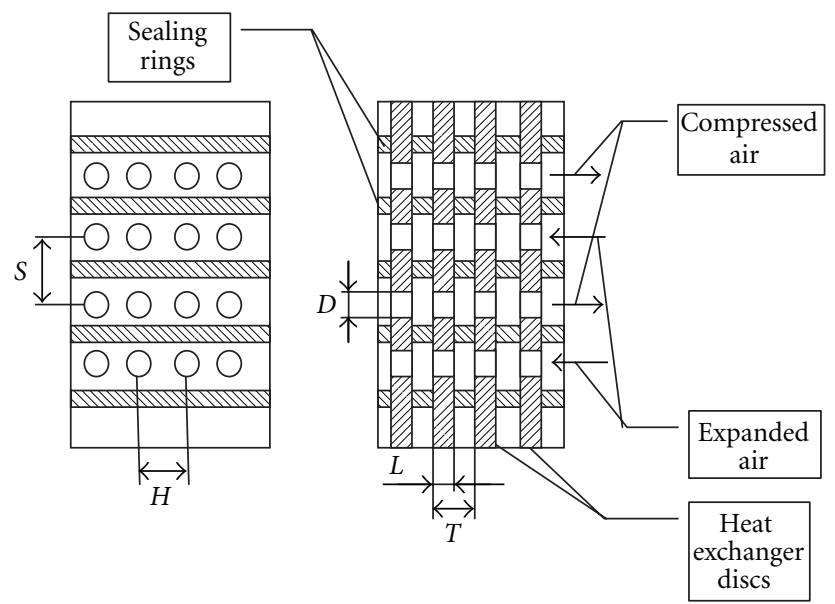

FIGURE 7: Fragment of microchannel recuperator.

temperature difference is practically impossible to obtain in heat exchanger that has normal diameters of channels $(3-4 \mathrm{~mm})$, but calculations in appendix show that the recuperator with micro channels (with diameter of $0.3 \mathrm{~mm}$ ) with the temperature difference of $5^{\circ} \mathrm{C}$ will have acceptable sizes (the diameter of disks of $384 \mathrm{~mm}$ and the length of disk stack of $275 \mathrm{~mm}$ ) for the engine that has power of $10.7 \mathrm{kWt}$. To manufacture this micro channel recuperator it is possible to use Micro Equipment Technology [14-16].

\section{Conclusion}

We propose to use the Ericsson cycle heat engine to transform heat energy of a solar concentrator to mechanical energy. At present the Stirling and the Rankine cycles are used for this purpose. The problem of these cycles is relatively low Carnot efficiency. For practically developed Stirling and Rankine heat engines the Carnot efficiency reaches 0.6. We want to obtain the Carnot efficiency higher, for example, 0.8-0.9. A special computer program was developed for estimation of parameters for the Ericsson cycle heat engine. Experiments with this program show that Ericsson cycle can have Carnot efficiency up to 0.88 .

Micro channel recuperator for Ericsson heat engine is proposed. This recuperator has the volume about 32 liters

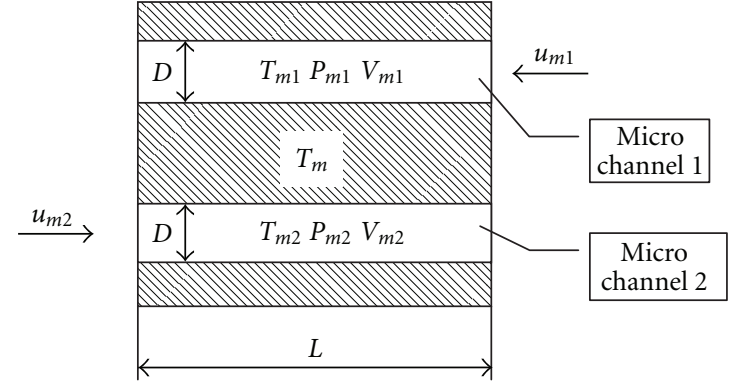

Figure 8: Pair of microchannels.

and permits us to create the Ericsson engine with power of some kWts. For this purpose it is necessary to have micro machine technology to produce this type of recuperator.

\section{Appendix}

\section{Evaluation of Recuperator Parameters}

Let us consider microchannel recuperator that has the following dimensions (Figure 7): $D=3 \cdot 10^{-4} \mathrm{~m}, S=6$. $10^{-4} \mathrm{~m}, H=4 \cdot 10^{-4} \mathrm{~m}, L=9 \cdot 10^{-4} \mathrm{~m}$, and $T=10^{-3} \mathrm{~m}$. The air in different base plates has different temperatures, but for rough estimation of recuperator parameters it is possible to consider the heat transfer process in 2 microchannels (Figure 8) that have mean temperatures:

$$
\begin{aligned}
& T_{m 1}=\frac{T_{3}+T_{5}}{2}=\frac{296+541}{2}=418.5^{\circ} \mathrm{K}, \\
& T_{m 2}=\frac{T_{2}+T_{4}}{2}=\frac{291+536}{2}=413.5^{\circ} \mathrm{K},
\end{aligned}
$$

where $T_{m 1}$ is the mean temperature of expanded (hot) gas, $T_{m 2}$ is the mean temperature of compressed (cold) gas, $T_{2}$ is the compressed gas temperature at the input of the recuperator, $T_{4}$ is the compressed gas temperature at the output of the recuperator, $T_{3}$ is the expanded gas temperature at the output of the recuperator, and $T_{5}$ is the expanded gas temperature at the input of the recuperator. All numerical values of the parameters in (A.1), (A.2), and below are drawn from the calculations made for engine version 2 (line 2 in Table 1).

Let us consider the pair or neighbor micro channels (Figure 8).

The channel with the expanded air we will term "hot channel," and the channel with compressed air we will term "cold channel." The pressure in the hot channel is

$$
P_{m 1}=2 \times 10^{6} \mathrm{~Pa},
$$

and the pressure in the cold channel is

$$
P_{m 2}=3.45 \times 10^{6} \mathrm{~Pa} .
$$

For our calculations we will suppose that the air speed of compressed air (cold channel) is

$$
u_{m 2}=0.5 \mathrm{~m} / \mathrm{s} .
$$


The air speed in the hot channel will be higher proportionally to the temperature relation of $T_{m 1} / T_{m 2}$ and pressure relation $P_{m 2} / P_{m 1}$. So we will have

$$
u_{m 1}=u_{m 2} \cdot \frac{T_{m 1}}{T_{m 2}} \cdot \frac{P_{m 2}}{P_{m 1}}=0.87 \mathrm{~m} / \mathrm{s} .
$$

To evaluate the heat transfer process in the micro channel it is possible to use Nusselt number. For laminar flow we accept this Nusselt number

$$
N_{u}=3.7 \text {. }
$$

Using this value we can calculate the heat transfer coefficient $h$ that shows how much of heat energy is transferred through 1 square meter of micro channel surface during 1 second if the temperature difference between the wall and the air equals to $1^{\circ} \mathrm{K}$ :

$$
h_{1}=h_{2}=\frac{k \cdot N_{u}}{D}
$$

where $h_{1}\left[\mathrm{~W} / \mathrm{m}^{2} \cdot \mathrm{K}\right]$ is the heat transfer coefficient in the first micro channel, $h_{2}\left[\mathrm{~W} / \mathrm{m}^{2} \cdot \mathrm{K}\right]$ is the heat transfer coefficient in the second micro channel, $k[\mathrm{~W} / \mathrm{m} \cdot \mathrm{K}]$ is the thermal conductivity of the air, $N_{u}$ is the Nusselt number, and $D$ is the micro channel diameter. In principle thermal conductivity of the air depends on the temperature, but the difference between the temperatures $T_{m 1}$ and $T_{m 2}$ is small, and it is possible to accept the thermal conductivity coefficient $k$ as equal to two channels. For the temperatures in (A.1) and (A.2) it will be

$$
k=0.035 \mathrm{~W} / \mathrm{m} \cdot \mathrm{K} .
$$

The substitution of the values of parameters to (A.8) will give

$$
h_{1}=h_{2}=432 \mathrm{~W} / \mathrm{m}^{2} \cdot \mathrm{K}
$$

Mass flow rate in the channel can be obtained from the equation:

$$
\varphi_{1}=\varphi_{2}=\rho_{2} \cdot \frac{\pi D^{2}}{4} \cdot u_{m 2},
$$

where $\varphi_{1}[\mathrm{~kg} / \mathrm{s}]$ and $\varphi_{2}[\mathrm{~kg} / \mathrm{s}]$ are the mass flow rates in the micro channel 1 and 2 , and $\rho_{2}\left[\mathrm{~kg} / \mathrm{m}^{3}\right]$ is the density of the air in the micro channel 2, $D[\mathrm{~m}]$ is the micro channel diameter, and $u_{m 2}[\mathrm{~m} / \mathrm{s}]$ is the mean speed of the air in the micro channel 2.

The density of the air in the micro channel 2 we will calculate using equation:

$$
\rho_{2}=\rho_{0} \cdot \frac{P_{m 2}}{P_{0}} \cdot \frac{T_{0}}{T_{m 2}}
$$

where $\rho_{2}\left[\mathrm{~kg} / \mathrm{m}^{3}\right]$ is the density of the air in the micro channel $2, \rho_{0}\left[\mathrm{~kg} / \mathrm{m}^{3}\right]$ is the density of the air at the normal conditions $\left(P_{0}=102 \mathrm{kPa}, T_{0}=293^{\circ} \mathrm{K}\right), \rho_{0}=1.2 \mathrm{~kg} / \mathrm{m}^{3}$. From (A.2) and (A.4) we have $T_{m 2}=413.5^{\circ} \mathrm{K}$ and $P_{m 2}=3.45 \cdot 10^{6} \mathrm{~Pa}$. Substitution of these values to (A.12) gives

$$
\rho_{2}=28.8 \mathrm{~kg} / \mathrm{m}^{3} \text {. }
$$

Substituting the value $\rho_{2}$ from (A.13) to (A.11) we obtain

$$
\varphi_{1}=\varphi_{2}=1.017 \cdot 10^{6} \mathrm{~kg} / \mathrm{s} .
$$

Now we have to evaluate the heat energy $Q_{1}[W]$ that is transferred from the air to the walls of micro channel 2 during $1 \mathrm{sec}$ and heat energy $Q_{2}[W]$ that is transferred from the walls of micro channel 2 to the air. In our case they are equal:

$$
Q_{1}=Q_{2}
$$

Due to equal heat energy and equal mass flow rate $\varphi_{1}=$ $\varphi_{2}$ it is evident that the temperature of micro channel walls $T_{m}$ (Figure 8) will be the following:

$$
T_{m}=\frac{T_{m 1}+T_{m 2}}{2}=416^{\circ} \mathrm{K} .
$$

To calculate the value $Q_{1}$ we can use the equation:

$$
Q_{1}=h_{1} \cdot A_{1} \cdot\left(T_{m 1}-T_{m}\right)
$$

where $A_{1}\left[\mathrm{~m}^{2}\right]$ is the area of the walls of the micro channel 1:

$$
A_{1}=\pi \cdot D \cdot L=84.8 \cdot 10^{-8} \mathrm{~m}^{2} .
$$

Substituting the parameter values to (A.17) we obtain

$$
Q_{1}=9.16 \cdot 10^{-4} \mathrm{~W} \text {. }
$$

Now we can evaluate decreasing of the air temperature $\Delta T_{C 1}$ in the micro channel 1 and increasing of the air temperature $\Delta T_{C 2}$ in the micro channel 2:

$$
\Delta T_{C 1}=\Delta T_{C 2}=\frac{Q_{1}}{\varphi_{1} \cdot C_{p}},
$$

where $C_{p}$ is the constant pressure heat capacity of the air. For our temperature $C_{p}=1014 \mathrm{~J} / \mathrm{kg} \cdot \mathrm{K}$.

Substitution of parameter values to (A.20) gives us

$$
\Delta T_{C 1}=\Delta T_{C 2}=0.89^{\circ} \mathrm{K} \text {. }
$$

Now we can calculate the number $N_{d}$ of disks that must contain our recuperator:

$$
N_{d}=\frac{T_{5}-T_{3}}{\Delta T_{C 1}}=275 .
$$

The number of holes $N_{h}$ in each disk we can calculate as follows:

$$
N_{h}=2 \cdot \frac{\varphi}{\varphi_{1}}
$$

where $\varphi[\mathrm{kg} / \mathrm{s}]$ is the mass flow rate of the air in the engine and $\varphi_{1}$ is the mass flow rate of the air in the micro channel. We have

$$
\varphi=V_{1} \cdot \rho
$$

In our calculations we use $V_{1}=0.01 \mathrm{~m}^{3} / \mathrm{s} ; \rho=24.6 \mathrm{~kg} / \mathrm{m}^{3}$ at the pressure 20 bar, so we obtain

$$
\varphi=0.246 \mathrm{~kg} / \mathrm{s}
$$


Substitution of the parameter values to (A.23) gives us

$$
N_{h}=484 \cdot 10^{3} \text {. }
$$

The whole number of the holes $N_{R}$ in the recuperator will be

$$
N_{R}=N_{h} \cdot N_{d}=133 \cdot 10^{6} .
$$

To make this number of the holes it is possible to use microequipment technology described in [14-16].

Let us evaluate the diameter of the disk. In Figure 7 we can see that the area $a_{1}$ occupied with one hole equal

$$
a_{1}=S \cdot H
$$

where $S[\mathrm{~m}]$ is the radial distance between holes and $H[\mathrm{~m}]$ is the tangential distance between the holes. For diameter of hole of $3 \cdot 10^{-4} \mathrm{~m}$ it is possible to have $S=6 \cdot 10^{-4} \mathrm{~m}$ and $H=4 \cdot 10^{-4} \mathrm{~m}$. In this case

$$
a_{1}=24 \cdot 10^{-8} \mathrm{~m}^{2} \text {. }
$$

The area of the disk $A_{d}$ will be

$$
A_{d}=N_{h} \cdot a_{1}=0.116 \mathrm{~m}^{2} .
$$

The diameter of the disc will be

$$
D_{\text {disk }}=\sqrt{\frac{4 \cdot A_{d}}{\pi}}=0.384 \mathrm{~m} .
$$

The step $T$ of the disks is $1 \cdot 10^{-3} \mathrm{~m}$, and the number of disks $N_{d}$ is 275 , so the length $L_{R}$ of the recuperator is

$$
L_{R}=T \cdot N_{d}=0.275 \mathrm{~m} .
$$

Now we can evaluate the air friction energy lost in the recuperator. The volumetric flow rate in the micro channel 1 equal

$$
V_{C 1}=\frac{\pi \cdot D^{2}}{4} \cdot u_{m 1}=6.15 \cdot 10^{-8} \mathrm{~m}^{3} / \mathrm{s},
$$

and in the micro channel 2 equals

$$
V_{C 2}=\frac{\pi \cdot D^{2}}{4} \cdot u_{m 2}=3.53 \cdot 10^{-8} \mathrm{~m}^{3} / \mathrm{s},
$$

and pressure drop $\Delta p$ in the micro channel is

$$
\Delta p=\frac{128 \cdot V_{C} \cdot \mu \cdot L}{\pi \cdot D^{4}}
$$

where $V_{C}\left[\mathrm{~m}^{3} / \mathrm{s}\right]$ is the volumetric air flow rate, $\mu[\mathrm{Pa} \cdot \mathrm{s}]$ is the dynamic viscosity, $L[\mathrm{~m}]$ is the channel length, and $D[\mathrm{~m}]$ is the channel diameter.

For $T_{m}=416^{\circ} \mathrm{K}$ dynamic viscosity

$$
\mu=2.35 \cdot 10^{-5} \mathrm{~Pa} \cdot \mathrm{s} .
$$

Substitution of parameter values to (A.35) gives us

$$
\begin{aligned}
& \Delta p_{1}=6.54 \mathrm{~Pa}, \\
& \Delta p_{2}=3.76 \mathrm{~Pa} .
\end{aligned}
$$

Power loss in the micro channel is

$$
W_{0}=\Delta p \cdot V_{C}
$$

For micro channel 1 we will have

$$
\begin{aligned}
& W_{C 1}=40.2 \cdot 10^{-8} \mathrm{Wt} \\
& W_{C 2}=13.3 \cdot 10^{-8} \mathrm{Wt} .
\end{aligned}
$$

The total power loss for air friction in the recuperator $W_{R}$ will be

$$
W_{R}=\left(W_{C 1}+W_{C 2}\right) \cdot \frac{N_{R}}{2}=36 \mathrm{Wt} .
$$

This value is small in comparison with the power of the engine that equals $10783 \mathrm{Wt}$ (line 2 of Table 1 ).

\section{Acknowledgment}

This work was supported partially by projects PAPIIT IN110510-3 and PAPIIT IN119610. The authours thank Dr. Neil Bruce for help in the paper preparation.

\section{References}

[1] E. Kussul, T. Baidyk, F. Lara-Rosano, J. M. Saniger, and N. Bruce, "Support frame for micro facet solar concentrator," in Proceedings of the the 2nd IASME/WSEAS International Conference on Energy and Environment (EE '07), pp. 300-304, Portoroz, Slovenia, 2007.

[2] E. Kussul, T. Baidyk, F. Lara-Rosano, J. M. Saniger, N. Bruce, and C. Estrada, "Micro-facet solar concentrator," International Journal of Sustainable Energy, vol. 27, no. 2, pp. 61-71, 2008.

[3] E. Kussul, T. Baidyk, O. Makeyev, F. Lara-Rosano, J. M. Saniger, and N. Bruce, "Flat facet parabolic solar concentrator with support cell for one and more mirrors," WSEAS Transactions on Power Systems, vol. 3, no. 8, pp. 577-586, 2008.

[4] B. Kongtragool and S. Wongwises, "A review of solar-powered Stirling engines and low temperature differential Stirling engines," Renewable and Sustainable Energy Reviews, vol. 7, no. 2, pp. 131-154, 2003.

[5] B. Kongtragool and S. Wongwises, "Performance of lowtemperature differential Stirling engines," Renewable Energy, vol. 32, no. 4, pp. 547-566, 2007.

[6] American Stirling Company (beautiful Stirking engines and kits), http://www.stirlingengine.com/.

[7] K. Hirata, Schmidt theory for Stirling engines, 1997, http://www.bekkoame.ne.jp/ khirata/academic /schmidt/schmidt.htm.

[8] A. Asnaghi, S. M. Ladjevardi, P. Saleh Izadkhast, and A. H. Kashani, "Thermodynamics performance analysis of solar stirling engines," ISRN Renewable Energy, vol. 2012, Article ID 321923, 14 pages, 2012.

[9] J. Chen, Z. Yan, L. Chen, and B. Andresen, "Efficiency bound of a solar-driven Stirling heat engine system," International Journal of Energy Research, vol. 22, pp. 805-812, 1998.

[10] L. B. Erbay and H. Yavuz, "Analysis of an irreversible Ericsson engine with a realistic regenerator," Applied Energy, vol. 62, no. 3, pp. 155-167, 1999.

[11] S. Bonnet, M. Alaphilippe, and P. Stouffs, "Energy, exergy and cost analysis of a micro-cogeneration system based on an Ericsson engine," International Journal of Thermal Sciences, vol. 44, no. 12, pp. 1161-1168, 2005. 
[12] E. Kussul and T. Baydyk, "Thermal motor for solar power plants," in Proceedings of the 3er Congreso Internacional de Ciencias, Tecnología, Artes y Humanidades, pp. 684-688, Coatzacoalcos, Veracruz, México, 2009.

[13] L. Ruiz-Huerta, A. Caballero-Ruiz, G. Ruiz et al., "Diseño de un motor de ciclo Ericsson modificado empleando energía solar," in Proceedings of the Congreso de Instrumentación SOMI 24, Mérida, Yucatán, México, 2009.

[14] E. M. Kussul, D. A. Rachkovskij, T. N. Baidyk, and S. A. Talayev, "Micromechanical engineering: a basis for the lowcost manufacturing of mechanical microdevices using microequipment," Journal of Micromechanics and Microengineering, vol. 6, no. 4, pp. 410-425, 1996.

[15] E. Kussul, T. Baidyk, and D. Wunsch, Neural Networks and Micro Mechanics, Springer, 2010.

[16] E. Kussul, T. Baidyk, L. Ruiz-Huerta, A. Caballero-Ruiz, G. Velasco, and L. Kasatkina, "Development of micromachine tool prototypes for microfactories," Journal of Micromechanics and Microengineering, vol. 12, no. 6, pp. 795-812, 2002. 

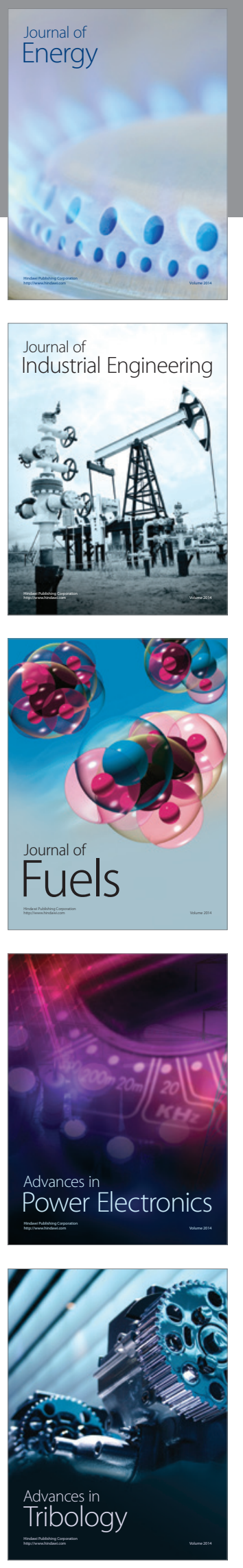
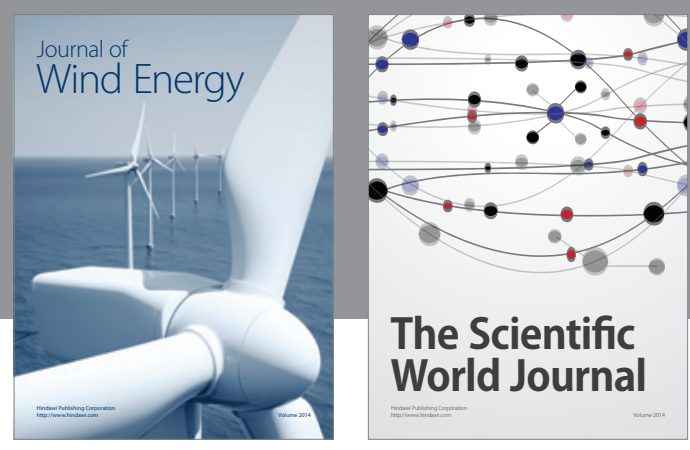

The Scientific World Journal

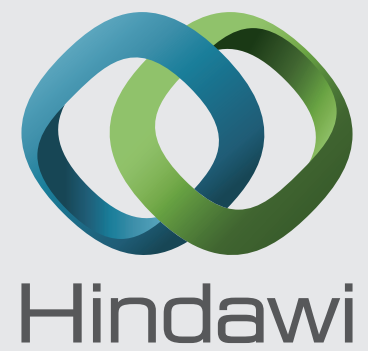

Submit your manuscripts at http://www.hindawi.com
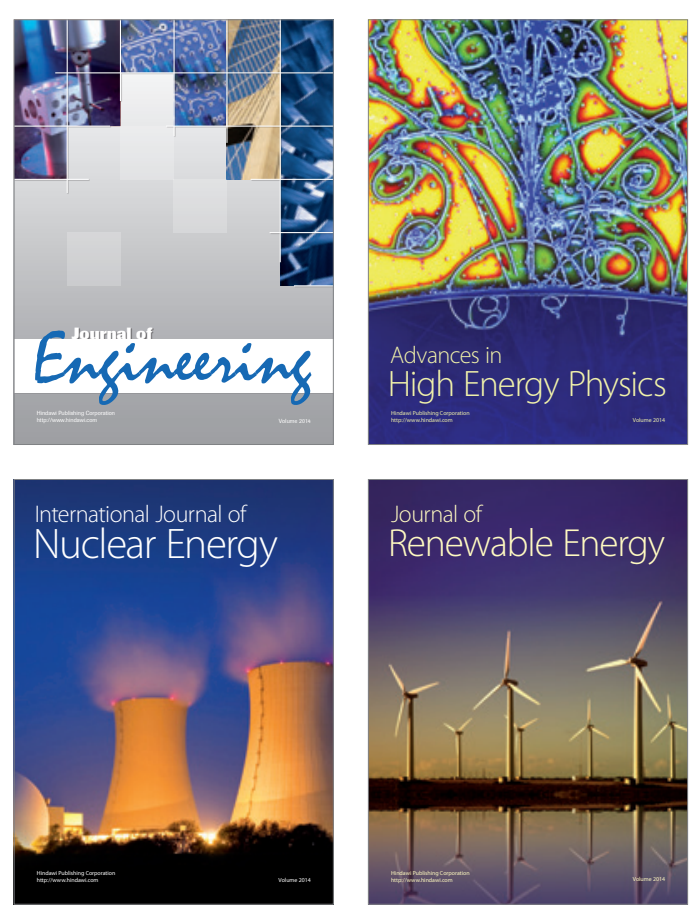

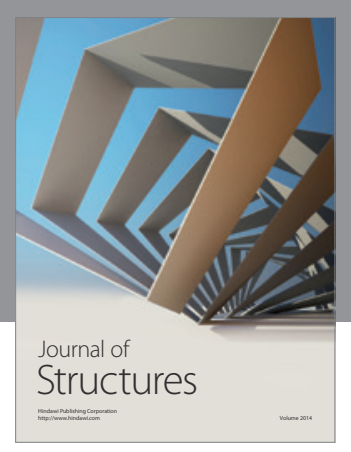

Rotating
Mechinery
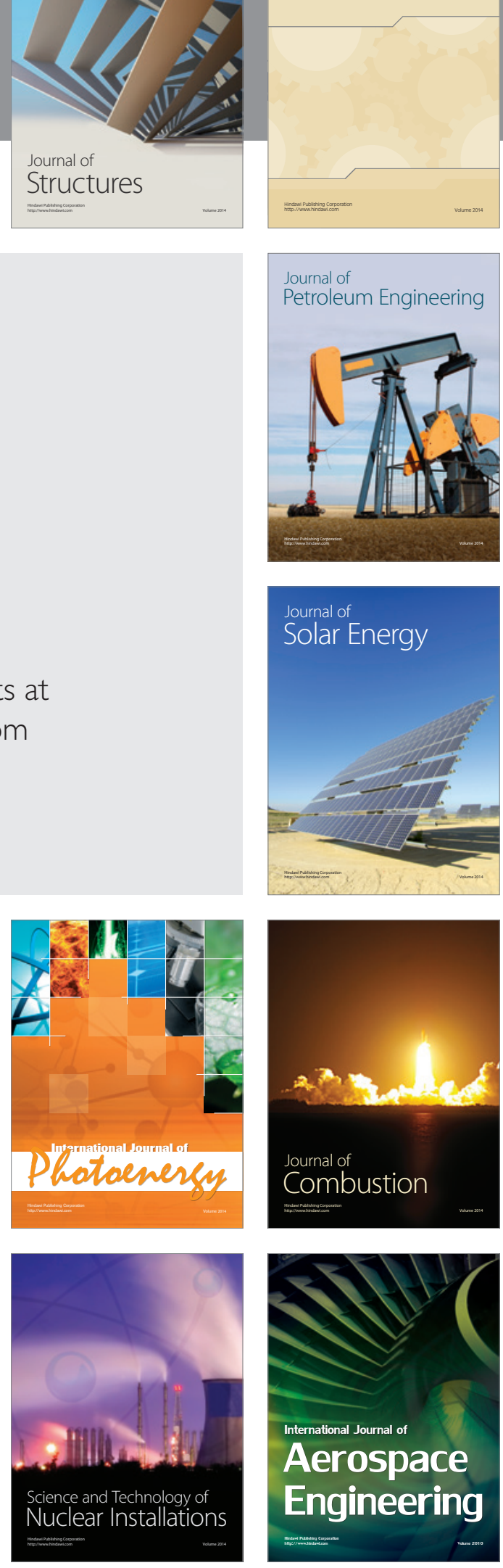